\title{
FOLCLORE Y ETNOGRAFÍA EN LOS MUSEOS VASCOS: UNA HISTORIA CENTENARIA, UNA DIACRONÍA ATEMPORAL
}

\author{
Iñaki Arrieta Urtizberea \\ Universidad del País Vasco / Euskal Herriko Unibertsitatea \\ (Donostia / San Sebastián)
}

\section{Resumen.}

El presente artículo describe y analiza la evolución de los museos de folclore y etnografía del País Vasco. Se centra especialmente en las representaciones del folclore y la etnografía en los museos vascos. Siguiendo las tendencias folcloristas europeas de principios del pasado siglo, los primeros antropólogos y etnógrafos vascos delimitaron el campo del folclore al estudio de la sociedad tradicional, popular y rural. Así, dicha sociedad fue objeto de representación en los primeros museos de folclore y etnografía. Establecida esa tipología de museos, su temática expositiva no ha variado a pesar de los importantes cambios políticos, económicos, sociales y culturales acaecidos en la sociedad vasca, en general, y en el mundo rural, en particular, durante los siglos XX y XXI. De este modo, la tesis del artículo es que las representaciones del mundo rural mostradas en las exposiciones permanentes de los sucesivos museos vascos de folclore y etnografía han permanecido constantes: el guión y los contenidos expositivos definidos por aquellos primeros antropólogos y etnógrafos se han mantenido a lo largo de la historia centenaria de dichos museos.

Palabras clave.

Folclore, etnografía, museos, exposiciones, cultura vasca. 


\title{
FOLKLORE AND ETHNOGRAPHY IN BASQUE COUNTRY MUSEUMS: A CENTURY-LONG HISTORY, A TIMELESS DIACHRONY
}

\begin{abstract}
.
This article describes and analyses the evolution of ethnographic and folklore museums in the Basque Country, focusing especially on folklore and ethnographic representations in Basque museums. In line with the European folklore tendencies of the beginning of the last century, the first Basque anthropologists and ethnographers delimited the field of folklore to the study of traditional, popular and rural society. Thus, this was the society represented in the first ethnographic and folklore museums.

Having establishing that typology of museums, their exhibition themes have not changed despite the important political, economic, social and cultural changes that have taken place in the Basque society, in general, and in the rural world, in particular, during the 20th and 21 st centuries. Hence, the hypothesis of the article is that the representations of the rural world on display in the permanent exhibitions of successive Basque ethnographic and folklore museums have remained constant: the script and the exhibition contents defined by those first anthropologists and ethnographers have been sustained throughout the one-hundred year-old history of these museums.
\end{abstract}

\section{Keywords.}

Folklore, ethnography, museums, exhibitions, Basque culture.

\section{INTRODUCCIÓN}

Históricamente en los países occidentales la actual antropología sociocultural ha estado integrada por tres disciplinas: la antropología sociocultural, propiamente dicha, la etnología y el folclore. Las dos primeras han tenido las culturas no occidentales como objeto de estudio; las denominadas culturas "primitivas", "exóticas", "naturales" o "sin escritura". El folclore, por su parte, ha estudiado las "culturas populares" occidentales. Esto llevó, a su vez, a la creación de dos tipos de museo: los museos de antropología y los museos de folclore. Aquella división disciplinaria comenzó a diluirse a partir de los años 60 del pasado siglo, cuando los antropólogos y los etnólogos se lanzaron a estudiar también las sociedades occidentales. Así, los actuales antropólogos analizan cualquier tipo de sociedad o de cultura. Esa convergencia disciplinaria ha tenido a su vez su repercusión en el campo de los museos. Aquella clasificación museística se ha diluido en gran medida, si bien en algunos países se sigue manteniendo.

Ese proceso de convergencia ha conducido, en algunos países como el Estado español, a la exclusión del término "folclore" del ámbito académico y del museístico. La actual antropología sociocultural lo ha absorbido. No obstante, en este artículo retomaremos 
otra vez dicho término, en primer lugar, porque el folclore es la disciplina que se ha ocupado históricamente de la cultura popular del País Vasco ${ }^{1}$, y, en segundo lugar, porque delimita el tipo de museo que vamos a analizar en este artículo: los museos de folclore y etnografía. En el País Vasco el término "etnografía" ha ido de la mano del de "folclore", empleándose indistintamente, si bien, actualmente, predomina el primero. Por tanto, en los territorios vascos el folclore y la etnografía se han ocupado de la cultura popular, especialmente de la rural como veremos más adelante, y los museos de folclore y etnografía, de representarla. En el País Vasco museos dedicados a otras culturas no occidentales apenas se han dado.

A lo largo de las siguientes páginas abordaremos, por un lado, la evolución de los museos de folclore y etnografía, desde sus orígenes a principios del siglo XX hasta la actualidad. Por otro, describiremos y analizaremos cómo se ha ido representando la sociedad rural vasca a lo largo de dicha evolución.

\section{FOLCLORE, ETNOGRAFÍA Y MUSEOS}

Hace unas décadas Joan Prat escribía: "La evolución histórica del folklore como disciplina está marcada por una serie de factores y circunstancias complejas y contradictorias, que difícilmente admiten explicaciones simplistas y unívocas" (1994:312). Efectivamente, una mirada al devenir de dicha disciplina nos muestra su diversidad y complejidad (Velasco, 1990). Sus propuestas teóricas y su objeto de estudio han variado de un país a otro, y han cambiado también a lo largo del tiempo (Noyes, 2012). No obstante, siguiendo a Raymond Williams (2003: 149-150), se puede definir el folclore como aquella disciplina que describe y analiza lo popular, lo rural, lo preindustrial y lo tradicional. Aunque estos cuatro ámbitos han delimitado el campo del folclore, está claro que, a su vez, muestran una gran complejidad y diversidad de referencias (García García, 1998: 12-13). Estos se han ido reformulando a lo largo del tiempo, incluso desapareciendo alguno de ellos, como lo preindustrial o lo rural, de algunas recientes propuestas folcloristas. En todo caso, especialmente a finales del siglo XIX y durante las primeras décadas del siglo XX, lo más problemático no fue que los folcloristas hubieran establecido un tipo determinado de objeto de estudio, sino su trasfondo político: su oposición a la modernidad y su vinculación con algunas ideologías, como veremos más adelante.

1. Al referirnos al País Vasco, lo hacemos incluyendo los cuatro territorios ubicados en el Estado español en los que se ha desarrollado la cultura vasca: Gipuzkoa, Bizkaia, Araba/Álava y Nafarroa/Navarra (Caro Baroja, 1971). En la actual configuración político-administrativa del Estado español, los tres primeros territorios constituyen la Comunidad Autónoma del País Vasco y el último la Comunidad Foral de Navarra. En este trabajo no se tiene en cuenta los territorios vascos situados en el Estado francés. A lo largo del texto utilizaremos las actuales denominaciones de las entidades territoriales. 
El origen de los museos de folclore se puede situar a finales del siglo XIX cuando el museo al aire libre Skansen (Suecia) abrió sus puertas. Eran años en los que la modernidad, con sus procesos de industrialización y de urbanización, estaba cambiando bruscamente las sociedades occidentales. Un nuevo tipo de sociedad comenzaba a emerger en las ciudades, estableciéndose nuevas relaciones culturales, sociales, económicas y políticas, y dejando obsoletas las precedentes. Así, el mundo rural pasó a convertirse en un referente cultural, social y político para muchos de los individuos que integraban aquellas nuevas ciudades emergentes. Al plantearse como alternativa al espacio industrial y urbano, el mundo rural se resignificó: éste se idealizó y romantizó. En esta resignificación tomaron parte activa los folcloristas y los museos que ellos impulsaron (Davis, 2011: 195; Kavanagh, 1991: 199-200). Como afirma Howard Wight Marshall, se trataba de reivindicar y representar una "edad de oro de lo popular" (1977: 393). No obstante, esa idealización y su representación no era algo que atañese solamente a unos folcloristas y a unas élites que se mostraban contrarios a la modernidad. Había también una demanda social importante para ver y recordar aquel mundo rural idealizado en los museos de folclore (Desvallées, 2000: 16-17).

La rápida expansión del folclore y sus museos no se hubiera dado probablemente, si no hubieran pasado a ser un elemento legitimador de determinados planteamientos ideológicos (Desvallées, 2000: 15-16; Velasco, 1990: 140). Especialmente para los nacionalismos, el pasado o, mejor dicho, su interpretación, ha sido clave para reivindicar sus demandas políticas (Lowenthal, 1998: 84; Smith, 2000: 211) y los museos de folclore han cumplido un papel legitimador al representar dicho pasado (Marshall, 1977: 395). No obstante, este papel, no era -ni lo es en la actualidad-algo específico de ese tipo de museos. Más bien tiene ver con la esencia misma de dicha entidad cultural; a saber, la de ser un espacio para la representación de las memorias y las identidades (Crooke, 2007: 13-14; Duncan, 2007: 24).

El rango de ideologías que se valieron de los museos de folclore fue muy amplio. Aquél va desde la perspectiva socialista, antirracisa y antifascista del Museo de Artes y Tradiciones y Populares, impulsado por Georges-Henri Rivière (Poulot, 2005: 32), hasta los heitmatmuseem que se crearon durante el nazismo (Gorgus y Chabaud 2000: 57-58), pasando por las imágenes desplegadas por los museos norteamericanos (Davis, 2011: 195), ensalzando al noble colonizador y al inmigrante competente: el sueño americano.

Así comenzó la gran expansión y consolidación de los museos de folclore. En primer lugar, en los países del norte de Europa, a continuación se generalizaron en el centro y el sur del continente (Rivière, 1936: 61-63), algo más tarde en Gran Bretaña, especialmente en Escocia y Gales, llegando finalmente a los Estados Unidos de Norteamérica y a Canadá (Marshall, 1977: 395). 
La Segunda Guerra Mundial frenó todo aquel dinamismo, volviéndose a recuperar en los años 60 y 70, pero con unos principios y unos objetivos harto diferentes. Como sostienen Jong y Skougaard (1992: 156) aquellas teorías folcloristas se habían vuelto obsoletas y Europa ya no se parecía a la del final del XIX. Tal vez, la principal muestra de ese cambio en los museos de folclore y etnografía se expresó en la emergencia de la Nueva Museología y en su materialización en los ecomuseos (Rivière, 1985: 182-185). Así, ya no se trataba de representar aquel mundo rural romántico, sino de establecer instalaciones museísticas y patrimoniales que hablaran del pasado, no idealizado, de las comunidades rurales, y también de su presente e, incluso, de su futuro. En esos ecomuseos y en otros proyectos patrimoniales semejantes se trataba, por ejemplo, de abordar cuestiones ecológicas, de las relaciones entre el mundo rural y urbano (Rautenberg, Micoud, Bérard y Marchenay, 2000: 9-10) o de la implementación de nuevas actividades económicas y de nuevos tipos de agricultura (Chevallier, Chiva y Dubost, 2000: 26). La cuestión identitaria tuvo también su importancia, aunque en un orden algo diferente al acaecido en las décadas precedentes. Un "espíritu de resistencia al olvido de la identidad bajo la dominación o incluso la opresión de un poder central" (Duclos y Veillard, 1992: 129) estaba en la base de aquella nueva museología que reivindicaba una identidad local propia frente a la nacional o global (Chaumier, 2005: 23-24). Así, se abrieron, con diferentes denominaciones, nuevos museos de folclore y etnografía. Sin embargo, a pesar de las innovaciones museológicas, museográficas, socioculturales y, también, políticas de la Nueva Museología y propuestas similares, una gran mayoría de los museos que se crearon siguieron reproduciendo el pasado rural idealizado que divulgaron aquellos primeros museos de folclore y etnografía (Davis, 2011: 266-267; Kavanagh, 1991: 194195; Roigé, 2007: 25).

En los últimos años se ha dado un aumento considerable en la creación de museos (Mairesse, 2011: 300) entre los que están los de folclore y etnografía. Por ejemplo, en España de los 262 museos de etnografía y antropología censados por el Ministerio de Educación, Cultura y Deporte², 182, un 70\%, se han creado entre los años 1990 y 2009. En Europa también ha aumentado considerablemente el número de ecomuseos (Davis, 2011: 135), si bien los hay que no se centran exclusivamente en cuestiones rurales. Esa proliferación de museos ha venido impulsada, en gran medida, por la mercantilización de la cultura, en general, y del patrimonio cultural, en particular. Con el objetivo de fomentar el desarrollo local, atrayendo turistas al territorio, se han creado muchos museos de folclore y etnografía. Sin embargo, en muchos de estos nuevos museos no se ha dado ninguna innovación museográfica: siguen reproduciendo en sus exposiciones las imágenes idealizadas y románticas establecidas a finales del XIX por los folcloristas. No obstante, los hay que han intentado superar dichas imágenes, reinventándose en nuevos

2. http://www.mcu.es/culturabase/cgi/axi [Consultado 20 de marzo de 2015]. 
proyectos. Así, algunos museos han presentado la sociedad rural, pasada y presente, en su complejidad y diversidad. Otros se han encaminado a la representación de las culturas europeas en su conjunto (Mazé, Poulard y Ventura, 2013: 9-10; Rogan, 2003: 51; Roigé, 2007: 22; Roigé, Boya y Alcalde, 2010). Entre estos museos reinventados tenemos el Musée des civilisations de l'Europe et de la Méditerranée, el Museum Europäischer Kulturen o el Nederlands Openluchtmuseum.

\section{FOLCLORE, ETNOGRAFÍA Y MUSEOS EN EL PAÍS VASCO}

Antes de abordar la evolución de los museos de folclore y etnografía, analizaremos cómo los primeros antropólogos vascos definieron el folclore y qué propuestas museográficas realizaron. Su análisis es esencial ya que ellos establecieron el guión y los contenidos de las exposiciones que se irán reproduciendo en los sucesivos museos del país a largo de los siglos XX y XXI.

Aquellos primeros antropólogos son: Telesforo de Aranzadi (1860-1945), José Miguel de Barandiarán (1889-1991) y Julio Caro Baroja (1914-1995). Barandiarán, el principal representante de los estudios del folclore del país, se implicó, tal vez, algo menos en los proyectos museológicos: "Él distinguía el rescate de elementos materiales relativos a un modo de vida, que es el objeto de la museografía, del de aquellos otros que atañen a la cultura espiritual" (Arregi, 1999: 346). Y a él le interesó particularmente lo segundo. No obstante, colaboró con los museos vascos indicando, por ejemplo, qué y cómo debían recoger el material etnográfico o estableciendo redes de colaboradores con los museos. En los casos de Aranzadi y Caro Baroja, la implicación fue mayor. Redactaron algunos proyectos museográficos que analizaremos a continuación. En dichos proyectos la influencia de Skansen fue notoria (Aranzadi, 1910: 21; Caro Baroja, 1944: 6).

Para Aranzadi "la cultura del pueblo, la verdaderamente popular que, por no acostumbrar la historia escrita apenas más que á espumar la vida de las naciones, queda abandonada en el hondón, es lo que constituye el objeto de su etnografía o folk-lore" (1911: 127-128). Y esta cultura popular es "la que posee el pueblo en sí, la que éste conserva y transforma, desarrollándola sobre la base de la tradición" (1919: 365) y cuya base es "rural" (Caro Baroja, 1986: 259; Goicoechea Marcaida, 1984: 197). De este modo, Aranzadi estableció las bases del folclore vasco, siguiendo a los folcloristas europeos. Así, emprendió la tarea de recoger la cultura material de la sociedad rural vasca y de exponerla en los museos. La tarea del conservador del museo, según Aranzadi, era la de recoger objetos que tuvieran una hechura casera, sencilla y sin pretensiones, y que tuvieran que ver con la casa, el ajuar, la indumentaria, los adornos, los utensilios para hilar y tejer, los juegos y juguetes, 
los instrumentos musicales, los aperos, los oficios, la medicina y el culto populares, las fiestas, los bautizos, las bodas, y los funerales y enterramientos (Aranzadi, 1910: 26-31). Caro Baroja, siguiendo en cierta medida a su "maestro" Aranzadi (1944: 7), redactó, entre otros, dos breves proyectos para los museos etnográficos de Bizkaia y Nafarroa/ Navarra, y uno, más extenso, para el Museo Nacional del Pueblo Español, del cual fue su director. En este último, publicado en los años 40, especificó claramente qué se debía recoger y exponer en los museos de folclore; "materiales que reflejen el estado social inmediatamente anterior a la gran progresión del industrialismo moderno" (1944: 8). Tal vez, la diferencia más significativa con respecto a su "maestro" fuera que la recogida de material no se tenía que reducir solamente a los "más humildes". Caro Baroja defendía que las clases "poderosas" debían tener también su sitio. Los temas que aparecen en los guiones de sus diferentes proyectos son: a) la vida material (vivienda y localidad, pastoreo, agricultura, trabajos del hogar, industrias rurales y comercio), b) la vida social (del nacimiento a la muerte) y c) la vida cultural (cultos, ritos, literatura y música). Un guión que siguió, por cierto, en algunas de sus monografías escritas.

De este modo los dos antropólogos establecieron las bases de los museos de folclore y etnografía, que abordaremos posteriormente, deteniéndonos en algunos casos concretos.

El folclore vasco, al igual que en otras partes de Europa, tampoco escapó a la controversia política, especialmente en lo relativo a su vinculación con el nacionalismo. Sin embargo, en lo que respecta a Aranzadi y Caro Baroja dicha relación no ha lugar. Acerca del primero, Luís Hoyos sostenía que "este amor a Vasconia, le llevó a un regionalismo absoluto, pero jamás, sin excepción alguna, a un nacionalismo definido" (Goicoechea Marcaida, 1985: 105). De Caro Baroja es conocido su rechazo a los nacionalismos. Tal vez, la figura de Barandirán sea la más problemática en cuanto a si legitimó, o no, el nacionalismo vasco. Al respecto hay interpretaciones dispares (Azcona, 1984: 105; Castilla Urbano, 2002: 51; Prat, 1991: 13-14; Zulaika, 2000: 105-110). En todo caso, él negó esa relación reiteradamente, manifestando su "gran satisfacción por no haber incorporado nunca mi actuación a ningún partido político” (Barandiarán Irízar, 1984: 195).

\section{EVOLUCIÓN DE LA CREACIÓN DE MUSEOS EN EL PAÍS VASCO}

La evolución de la creación de museos a lo largo de los siglos XX y XXI ha estado condicionada por los grandes cambios políticos acontecidos en el Estado español (Díaz Balerdi, 2008, 2010, Ortiz y Prats, 2000). Los hitos principales han sido la Guerra Civil del 36 y la muerte del dictador Franco en 1975. 
La aparición de los museos en el País Vasco ${ }^{3}$ arrancó en los albores del siglo XX, algo más tarde que en Europa como hemos visto anteriormente. El primero en abrirse al público fue el Museo Municipal de Donostia-San Sebastián en 1902. Los temas expuestos en su primera exposición tenían que ver con la arqueología, la historia y las bellas artes. Abordando esas mismas cuestiones, se inauguró en 1910 el Museo de Navarra en IruñaPamplona. Posteriormente se abrieron en Bilbao el Museo de Bellas Artes, el Museo de Arte Moderno -ambos constituyen el actual Museo de Bellas Artes-, el Museo Arqueológico de Vizcaya y Etnográfico Vasco, y el Museo de Reproducciones Artísticas. Otros tres se inauguraron en Gipuzkoa: el Aquarium, el Museo de Armería y el Museo de Ignacio Zuloaga. También la iglesia comenzó a presentar sus colecciones en aquellas primeras décadas, exponiéndolas en la Real Colegiata de Roncesvalles y en la Diócesis de Vitoria-Gasteiz. Aunque el primer museo que contó con el término "etnográfico" en su denominación fue el de Bizkaia, abierto en 1921, el Museo Municipal de Donostia-San Sebastián ya se había hecho célebre gracias a su sección de etnografía, siendo Aranzadi uno de sus principales mentores.

La Guerra Civil y la posterior Dictadura condicionaron claramente la evolución museística del País Vasco. Algunas temáticas desparecieron o se resignificaron, como veremos más adelante, y otras se consolidaron con fuerza. Entre éstas estaban aquéllas que tenían que ver con el catolicismo, abriéndose dos museos diocesanos y otros dos dedicados a la vida de los santos Valentin Berrio-Otxoa e Ignacio de Loiola. Otros dos nuevos museos se centraron en temas militares, tres en bellas artes y otros tres en arqueología e historia. Excepciones a toda esa dinámica religiosa, artística, histórica y militar, fueron el Museo del Pescador en Bermeo, el Museo Etnográfico en Berrioplano y la rehabilitación de la ferrería de Mirandola.

Durante la década de los 70, años del fin de la Dictadura y el inicio de la transición a la Democracia, no se abrió prácticamente ningún museo al público. En los 80 se inauguraron 16, siendo, en general, iniciativas modestas llevadas a cabo en municipios pequeños. En esa década aparecieron con fuerza el folclore y la etnografía en las exposiciones, creándose cinco museos de este tipo. Asimismo, emergieron otros nuevos contenidos expositivos como los dedicados a las figuras históricas de Simón Bolivar o Zumalacarregui, al medio ambiente, a los fósiles o a la medicina.

3. No es nada fácil establecer un registro riguroso de museos en el País Vasco ya que las instituciones públicas han utilizado diferentes criterios para determinar qué es un museo, una colección, un centro de interpretación o una sala expositiva. Así que consultando las listas establecidas por las diferentes administraciones públicas y los trabajos de Díaz Balerdi $(2008$, 2010), hemos confeccionado nuestra relación de museos. Asimismo, a lo largo de la centenaria historia de los museos vascos, algunos de ellos se han fusionado, otros se han reinventado totalmente, algunos no han abierto sus puertas al público aun contando con colección y personal. Así que el objetivo de nuestro registro es determinar tendencias y no establecer un inventario riguroso ya que éste dependerá de los criterios museísticos utilizados que, a su vez, son bastante flexibles. Las fechas de referencia son las de apertura al público 
En la última década del siglo XX, el número de museos se duplicó, respecto a la década anterior, alcanzando los 36. La temática expositiva se siguió ampliando, dando cabida a la industrialización, la paz, el nacionalismo, la policía vasca, los requetés, además de los ya habituales dedicados a la arqueología y las bellas artes. Del total de los museos abiertos al público, en 16 la etnografía y el folclore eran la temática principal u ocupaba una presencia importante. Así, en Gipuzkoa se abrieron cinco; en Bizkaia, tres; en Araba/ Álava, seis; y en Nafarroa/Navarra, dos.

La primera década de este siglo se podría calificar como la del "boom museístico". Se abrieron al público 70 nuevos museos. Otros nuevos temas se fueron incorporando como, por ejemplo, el fútbol y la ciencia. En lo relativo al folclore y la etnografía, del total de nuevos museos, 19 abordaban esa temática, aunque su distribución por provincias fuera muy desigual. Así, En Bizkaia y Araba/Álava se abrieron solamente dos museos. Sin embargo, en Gipuzkoa se inauguraron nueve y en Nafarroa/Navarra, ocho. Hay que destacar que muchos de esos museos han sido creados por empresas y establecimientos alimentarios, en los que se explica la actividad que desarrollan tal y como se realizaba tradicionalmente. Por lo general, son establecimientos museísticos modestos.

Para concluir, en lo que llevamos de década, la apertura de museos se ha ralentizado respecto a la década anterior. Hasta la fecha, se han inaugurado 17. El motivo de dicha ralentización es la actual crisis económica. De todos ellos, solamente tres tienen que ver con el folclore y la etnografía.

\section{LOS PRIMEROS MUSEOS DE FOLCLORE Y ETNOGRAFÍA}

De los casi 170 museos que hemos registrado a lo largo del siglo XX y XXI, casi un 30\% han sido, parcial o íntegramente, de folclore y etnografía. Un número significativamente importante e imposible de abordar en lo que resta de artículo. Así que nos detendremos en algunos de ellos con el objetivo de mostrar cómo la sociedad rural vasca se ha ido presentando en ellos a lo largo de estos dos siglos.

Comenzaremos con los dos primeros museos de ese tipo que se crearon: El Museo Municipal de Donostia/San Sebastián y el Museo Arqueológico de Vizcaya y Etnográfico Vasco en Bilbao.

El Museo Municipal de Donostia/San Sebastián, posteriormente denominado Museo San Telmo, se orientó en un principio a la arqueología, la historia y las bellas artes, si bien para la segunda década del pasado siglo ya contaba con una sección de etnografía vasca, siguiendo las indicaciones de Aranzadi. Asimismo, la exposición permanente contaba con un pequeño espacio en el que se podía ver una habitación y una cocina del País Vasco de los siglos XVI-XVII. Hasta la Guerra Civil del 36 dicha sección se amplió considerablemente, alcanzando un reconocimiento significativo en España. La contienda 
militar frenó todo aquella actividad folclorista y etnográfica. No obstante, en la década de los 50, su presencia en la exposición era notable. Ocupaba tres galerías que estaban llenas de "objetos de folklore guipuzcoano, que merecen atención detallada, pero que sería imposible de numerar" (Gaya Nuño, 1955: 624). Aquellos objetos representaban los oficios artesanales, los deportes vascos, la pesca o las actividades agropecuarias del caserío. En la exposición se podía ver todavía la habitación y la cocina del XVI-XVII y también una maqueta de un dolmen y serie de estelas discoidales. Así, hasta la reciente remodelación del Museo en el 2011, los contenidos y el guión de las salas destinadas al folclore y la etnografía siguieron siendo los establecidos por Aranzadi, si bien, el espacio que ocupaban había aumentado considerablemente (Aguirre Sorondo, 2002).

El Museo Arqueológico de Vizcaya y Etnográfico Vasco, como su nombre indica, ha contado desde sus orígenes con dos secciones definidas claramente. Por un lado, la arqueológica e histórica, y, por otro, la folclórica y etnográfica. En lo que respecta a esta segunda, la exposición inicial estuvo integrada por "la instalación de una cocina y un dormitorio tradicionales, de trajes, aperos de labranza, utensilios de trabajo, redes y aparejos de pesca, trabajos en hierro, cerámica..." (Museo Arqueológico, Etnográfico e Histórico Vasco: 1996: 6). En aquellos primeros años colaboraron con el museo Barandiarán y Aranzadi. Al igual que en el de Donostia-San Sebastián, la Guerra Civil paralizó toda aquella actividad museística. No obstante, en la década de los 40 Caro Baroja redactó un plan de renovación con el objetivo de hacer "una instalación que no dé reproches de 'aldeanismo' y otras críticas fáciles y molestas" (Caro Baroja, 1958: 120). Aunque no se llegó a materializar, el plan recogía las ideas que hemos presentado anteriormente acerca de su proyecto para el Museo Nacional del Pueblo Español. En los años 70, la exposición se mantenía, a grandes rasgos, igual. Contaba con salas destinadas al arte popular, la cerámica, la mar, el hierro, el caserío y los deportes populares, todo ello con el objetivo de mostrar "un apacible ambiente patriarcal, propio del pasado bucólico, y el mobiliario está en consonancia con la sencillez de sus dueños, así como el ajuar, que ha de responder a los mimos postulados culturales" (Grande, 1978: 41). Actualmente el folclore y la etnografía ocupan dos plantas del edificio del museo. En él, como se indica en el panel de entrada, se pueden visitar "exposiciones relativas a las actividades tradicionales del País Vasco". Entre ellas hay dos salas, denominadas "Cultura Pastoril" y "El Mar de los Vasco", inauguradas en la década de los 90 , una gran maqueta de una ferrería, realizada en 1977, unas exposiciones de cerámica tradicional y de lozas y porcelanas vascas, un espacio dedicado a los deportes tradicionales y otro a la elaboración de telas de lino y de lana. En definitiva, la exposición del museo nos retrotrae al folclore tal y como lo definieron los primeros antropólogos vascos. 
Aunque la cultura material expuesta en esos museos de folclore a lo largo de todo un siglo no haya cambiado esencialmente, su significación sí que lo ha hecho, especialmente en su dimensión política. Como en Europa, la relación entre los museos de folclore, el nacionalismo y la identidad vasca fue objeto de debate político (Arrieta Urtizberea, 2006) que se vio drásticamente truncado tras la Guerra Civil. El nuevo Estado centralista, surgido tras la contienda militar, reinterpretó el folclore y lo puso al servicio de su nuevo proyecto identitario español (Ortiz y Prats, 2000: 243). En el caso del museo etnográfico de Bilbao, esa reinterpretación se visualizó claramente "en la nueva denominación que se dio al centro, Museo Histórico de Vizcaya” (Mujika Goñi, 1995: 292). Asimismo, tras la victoria franquista, las adquisiciones del museo debían tener un significado "neutro". No debían representar ningún elemento diferencial respecto a la unidad de España (Museo Arqueológico, Etnográfico e Histórico Vasco: 1996: 10). El Museo San Telmo, a su vez, se transformó en "un centro digno para la nueva España", tal y como aprobó su Junta tras la Guerra Civil. Sin embargo, a partir de los años 60 y 70 esa reinterpretación centralista del folclore comenzó a ser cuestionada con el resurgimiento de los movimientos políticos y culturales, como veremos a continuación.

Hay que destacar, además, que a partir de la década de los 50 la estructura económica y social del País Vasco comenzó a transformarse con la segunda industrialización. Esto supuso un cambio cultural, social y económico en el mundo rural. Muchos caseríos se abandonaron, otros se modernizaron y muchos baserritarrak o campesinos se hicieron obreros. Todo este proceso tuvo también su reflejo en los motivos que llevaron a la creación de nuevos museos de folclore y etnografía a partir de los años 80 .

\section{LOS MUSEOS DE FOLCLORE Y ETNOGRAFÍA DESDE LA DÉCADA DE LOS 80 HASTA LA ACTUALIDAD}

En ese proceso de transformación socioeconómica del país, aquella vinculación decimonónica entre el folclore y el mundo rural, como espacio de autenticidades identitarias, se vio reforzada otra vez. A ese proceso había que sumar, además, las reivindicaciones, entre otras, nacionalistas e identitarias que iban emergiendo a medida que la Dictadura se mostraba cada vez más débil. Por tanto, en aquel crisol sociopolítico y cultural, el folclore tuvo su papel y éste se reflejó en los primeros museos que se crearon tras la muerte del Dictador. Como ya se ha indicado, de los once que abrieron sus puertas en la década de los 80, casi la mitad fueron de folclore y etnografía. Entre ésos estaban los museos de Zalduondo y Artziniega. 


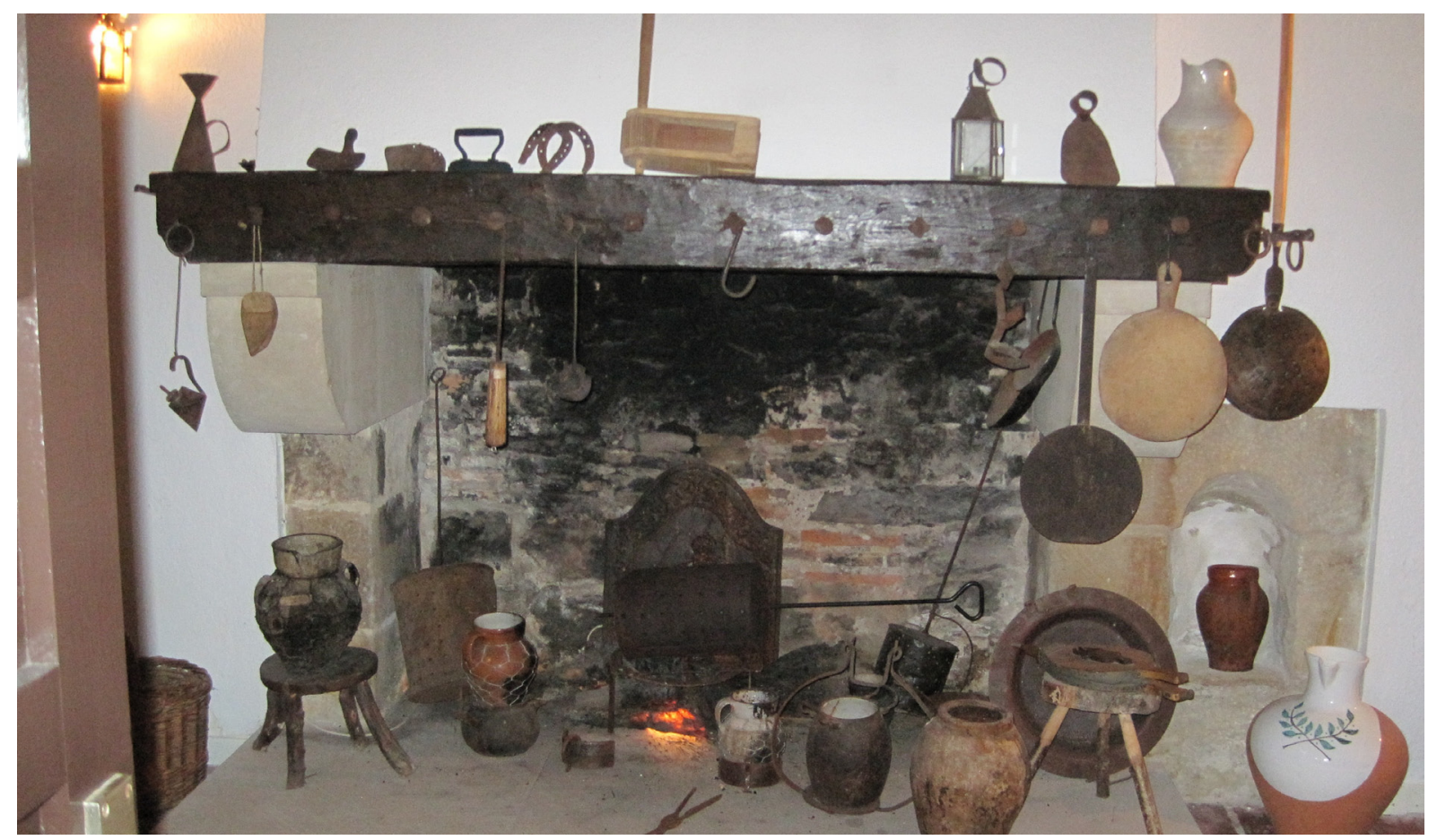

Foto 1: Exposición del Museo de Zalduondo. (Foto: Iñaki Arrieta).

Zalduondo es un pequeño municipio rural, actualmente de unos 200 habitantes, en Alaba/Álava. En la década de los 70, unos vecinos del municipio acordaron llevar a cabo una serie de iniciativas culturales, en el marco del conjunto de reivindicaciones políticas e identitarias que se estaban dando en el país (Apaolaza, 1987: 155). Entre aquellas iniciativas estaba la creación del museo de etnografía, que abrió sus puertas en 1982. Aunque hayan transcurridos más de 40 de años desde su inauguración, la exposición que se puede visitar en la actualidad mantiene el discurso inicial. El museo cuenta también con unas salas dedicadas a la historia y al arte local. En lo que se refiere a la sección etnográfica, ésta cuenta con la réplica de la chabola de un pastor y una cocina compuesta por un fuego bajo y un horno de pan. Hay también un pequeño espacio con aperos de labranza e instrumentos para trabajar el lino y la lana. Aperos más grandes junto a un telar, unas estelas y unas arcas se pueden ver en el patio del edificio. Por último, cuenta con un espacio dedicado al carnaval local, una fiesta recuperada en 1975 tras ser prohibida durante la Dictadura.

También en la década de los 70, en el municipio alavés de Artziniega, en la actualidad con algo menos de 2.000 habitantes, comenzó a gestarse la posibilidad de crear un museo etnográfico. "El motivo principal fue la continuada e inexorable pérdida de una época de artesanos [...] como consecuencia de la producción industrial, que pronto había hecho olvidar muchos de los oficios tradicionales. Por otra parte, la remodelación de las viviendas y caseríos provocó la pérdida de aperos y utensilios" (Asociación Etnográfica 
Artea, 2011: 9). Como en el caso de Zalduondo, fue un grupo de vecinos, impulsado por un sacerdote, el que acometió la creación del museo. En 1984 abrió sus puertas, trasladándose posteriormente al actual edificio. El museo, manteniendo más o menos el guión y los contenidos iniciales, es "más bien rústico, porque responde a una zona geográfica de condición agrícola, principalmente. Y nos hace descubrir el valor de lo pequeño, lo cotidiano, lo sencillo. En este sentido hace el intento de mostrar una realidad sociológica y espiritual del pasado a la que pertenecen los objetos exhibidos, pero que está en las raíces de esta sociedad actual y que, por esta razón, puede tener un efecto de catarsis, de dinamismo, de crítica o de contraste" (Asociación Etnográfica Artea, 2011: 67). El Museo cuanta con dos plantas. La planta baja es la más etnográfica y está dedicada a los oficios tradicionales (sastre, modista, zapatero, carpintero, herrero...) y al caserío y la agricultura, antes de la modernización y la mecanización. La segunda, cuenta con algunas salas folclóricas como las destinadas a los juegos, la música o la religiosidad popular. En el resto de salas se pueden ver la escuela, al ayuntamiento y los concejos, la tienda, la farmacia, la barbería o una vivienda burguesa. Aunque en estas salas se puedan ver objetos modernos, los espacios expositivos apelan al pasado preindustrial.

En la década de los 90, como ya hemos visto, aumentó el número de museos de folclore y etnografía que abrieron sus puertas. En total, 16: un 44\% del conjunto de los museos creados durante aquellos años. Uno de ellos fue el museo etnográfico del proyecto Parque Cultural de Zerain; un municipio rural, de algo más de 200 habitantes, situado en Gipuzkoa. $\mathrm{Al}$ igual que en Zalduondo y Artziniega, fue una iniciativa vecinal, si bien apoyada por el Ayuntamiento. Dicha iniciativa surgió en la década de los 70 y su objetivo fue hacer frente al proceso de inmigración y abandono que se estaba dando en el municipio. Se trataba, y así continúa, de un proyecto más ambicioso que el de los municipios alaveses ya que buscaba la mejora en las infraestructuras, la integración comunitaria, la mejora de la calidad de vida de los habitantes y la creación de un futuro económico viable en el municipio (Urla y Errekondo, 2010). Seguía, en cierta medida, los principios de la Nueva Museología. Entre las acciones concretas propuestas en el proyecto estaba la puesta en valor del patrimonio cultural y la creación de un museo etnográfico. Éste se inauguró en 1993 con objetos y "antiguas herramientas y aperos de caserío" (Leizaola, 1997: 397) recogidos previamente durante la realización de un inventario en el término municipal. Aquel museo, inaugurado hace más de veinte años, se puede visitar en la actualidad en el desván de la antigua casa rectoral. Es un espacio relativamente pequeño y cuenta con doce espacios dedicados a la historia del municipio, el arte sacro, los personajes locales, la caza y pesca, la apicultura, el pastoreo, la agricultura, la casa, el carboneo, la cantería y la minería, y a diversos temas sociales. La exposición sigue la línea de los museos descritos hasta el momento, a excepción de la sección destinada a la minería. Ésta rompe con la imagen del mundo rural, ligada al caserío, de los museos de folclore y etnografía ya que muestra la importancia que tuvo la explotación de las minas de Aizpea, cerradas en 1951, 
en el municipio. Así, en el 2008 se abrió un centro de interpretación sobre dicha temática. No obstante, hay que subrayar que, si bien el museo etnográfico representa la ruralidad tradicional, el Parque Cultural impulsa diferentes iniciativas que tienen que ver con el presente de los espacios rurales. Entre otras están la producción y comercialización de productos con label de calidad o la apertura de agroturismos (Errekondo, 2011).

Si hasta el momento las exposiciones presentadas han sido llevadas a cabo en pequeños municipios rurales, a continuación nos detendremos en dos proyectos impulsados por las diputaciones forales de Gipuzkoa y Bizkaia. Dos administraciones públicas, de ámbito provincial, que cuentan con importantes recursos económicos y de personal.

El Museo de Euskal Herria (Museo del País Vasco) de la Diputación Foral de Bizkaia, ubicado a unos pocos metros de la Casa de Juntas de Gernika, lugar donde el Lendakari (Presidente) del Gobierno Vasco toma posesión de su cargo, abrió las puertas al público en 1991 con el objetivo de que fuera "un espejo para ver el pueblo de Euskal Herria" (Lorenzo, 2007) y sirviera de complemento a la Casa de Juntas de Gernika. La actual exposición permanente, reformulada hace nueve años, cuenta con tres grandes secciones, una por cada planta del edificio. La planta baja está dedicada a la historia del edificio, la prehistoria, el hábitat y el poblamiento, el territorio y los habitantes, y, para terminar, a la cartografía. Temas folclóricos y etnográficos están presentes en la sección "Hábitat y poblamiento". Ésta cuenta con dos áreas. En la primera hay una gran maqueta, bajo la denominación "Modelo de localidad rural". En dicha maqueta están reproducidos unos caseríos y unas casas urbanas, un palacio, un lagar, una borda, una casa de un indiano, una iglesia, una escuela, una ermita y un molino. El conjunto constituye una aldea bien organizada y en armonía. La segunda área, es una pequeña sala con maquetas de caseríos e iglesias locales. Subiendo las escaleras, se llega a la planta primera, que está dedicada principalmente a la historia política de los territorios de Euskal Herria. Por último, está la segunda planta destinada íntegramente al folclore y la etnografía. Los temas representados son los deportes vascos, los mitos y las creencias, las danzas, la música académica, la música popular, el euskara -la lengua vasca- y la gastronomía. El hilo argumental del conjunto expuesto en esa planta queda claro nada más entrar: "Euskal Herria es una tierra orgullosa de sus tradiciones, ha sabido preservar su idioma durante milenios, convertir sus trabajos en deportes, mantener ritos ancestrales y cocinar platos de sabor antiguo". Se trata de presentar preferentemente la tradición. Así, en los paneles se afirma, por ejemplo, que la danza es una de las mejores expresiones de la tradición, que la música popular se aleja de las normas académicas y bebe de la tradición o que los mitos y leyendas tienen orígenes paganos. Llama la atención que se haya incluido una sección dedicada a la música académica ya que rompe con lo popular del folclore. No obstante, aunque la tradición dirige el guión de esa planta, hay referencias a algunas expresiones y actividades culturales contemporáneas. Por ejemplo, se expone la obra del escritor Bernardo Atxaga (1951), hay una vitrina dedicada a los recientes campeonatos 
de "bertsolarismo" 0 se puede ver un apartado destinado a la "nueva cocina vasca".

Dela diputación vizcaína pasamos a la guipuzcoana para abordar una de las intervenciones museísticas, relacionada con el folclore y la etnografía, más importante llevada a cabo en el País Vasco. Corrían los años 90 cuando la Diputación Foral de Gipuzkoa se mostraba preocupada por el "grave problema que gravitaba sobre la protección del patrimonio rural, habida cuenta de la pérdida creciente de los valores intrínsecos de la arquitectura vernácula" (Izagirre, 2003: 108). Con el objetivo de paliar esa pérdida acordó la elaboración de un plan director de difusión de dicho patrimonio. Durante su redacción, la Diputación tuvo conocimiento de que los propietarios del caserío Igartubeiti (Ezkio-Itsaso), con más 400 años de antigüedad, querían derribarlo para hacer una vivienda unifamiliar. Para evitar dicha pérdida la Diputación compró el caserío en 1992. Dicha compra se justificó porque el mencionado caserío había conservado "con pocas alteraciones la mayor parte de su estructura y cerramientos de fachada de madera [... y por] su capacidad para representar a un amplio número de caseríos con características sociales, económicas o de asentamiento similares" (Santana, 2003: 30). De su larga historia, "se marcó el año 1630 como referencia a la hora de dirimir alternativas reconstructivas u otras situaciones en las que el concepto tiempo cobraría una valor fundamental" (Izagirre, 2003: 111). Así se puso en marcha un proyecto ambicioso de investigación y rehabilitación, desmontando y reconstruyendo el caserío según la referencia temporal señalada anteriormente. El caserío rehabilitado se abrió al público en el 2001.

Como el caserío debía representar fielmente el tipo de vivienda que era en el siglo XVII, se decidió construir en los aledaños un centro de interpretación en el que se pudiera presentar todo el material explicativo (Izagirre, 2003: 111). El centro de interpretación se abrió en el 2007. Cuenta con una recepción, una zona expositiva y otra lúdica. La zona expositiva está dividida en cinco módulos con un importante despliegue de nuevas tecnologías y recursos multimedias (Goenaga Maiza, Vives Almandoz, Ugarteburu Plazaola y Azpiazu Aizpeola, 2007). El primer módulo es "Un paseo por la historia”. Se trata de un pasillo de unos quince metros en el que se narra la historia de los caseríos desde su aparición hasta el siglo XIX, basándose en la evolución del propio caserío Igartubeiti. El siguiente módulo, "Vivir en el caserío", está compuesto de unas vitrinas con objetos y documentos que abordan los temas de la herencia, las creencias, la vestimenta y los aperos. En el tercero, "A vueltas con el caserío", se muestran las diferentes tipologías de caseríos a través de unos paneles gráficos. El cuarto módulo, “1630. Los vecinos de Igartubeiti”, se trata de un audiovisual en el que aparecen diferentes personajes de aquella época, narrando su biografía. Por último, “Trabajar en el caserío" consta de unas proyecciones simultáneas en las que se muestran los trabajos que se hacía en el siglo XVII.

4. Se trata de una competición de versos improvisados en euskara: http://www.bertsozale.eus/es/ bertsolaritza/historia [Consultado el 23 de marzo de 2015]. 
El caserío Igartubeiti abrió sus puertas en la primera década de este siglo durante el cual se inauguró el mayor número de espacios museográficos dedicados al folclore y etnografía. Muchos de ellos, como ya se ha señalado, estaban relacionados con la elaboración de productos alimentarios locales. Del conjunto de todos ellos, nos detendremos en la exposición del Museo Etnográfico Jorge Oteiza en el municipio rural del Baztan (Nafarroa/Navarra). Se encuentra concretamente en el núcleo de población de Elizondo, que cuenta con cerca de 3.500 habitantes. Es uno de los pocos museos de ese decenio que representa el mundo rural vasco en su conjunto.

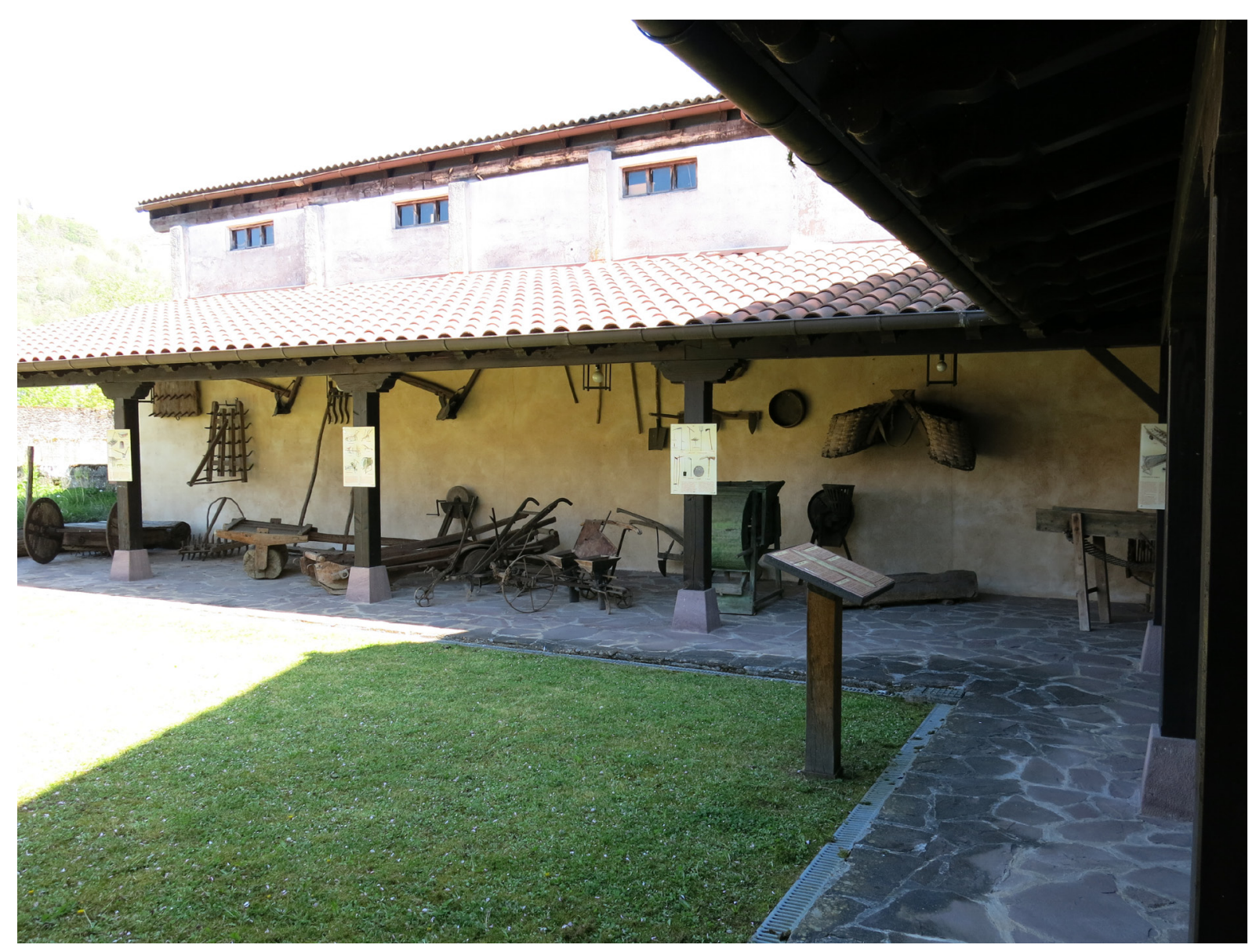

Foto 2: Exposición del Museo Etnográfico Jorge Oteiza. (Foto: Iñaki Arrieta).

Impulsado por unos vecinos, el Ayuntamiento y Jorge Oteiza, se abrió al público en 2003, en un edificio de tres plantas. La planta baja y la primera están destinadas a la etnografía y la segunda, al pintor Javier Ciga. El Museo comparte la planta baja con la oficina de turismo, muestra de la relación estrecha que en los últimos años se ha establecido entre, por un lado, el museo y, por otro, el turismo cultural y el desarrollo económico local. Siguiendo el guión de las exposiciones ya presentadas, la muestra se centra en el mundo rural preindustrial, aunque se puedan ver algunos aperos de 
fabricación industrial (sembradora de maíz, aventadora, grada de hierro, brabana...), pero en ningún caso motorizados. En la planta baja, nada más entrar, hay unas estelas discoidales $y$, a continuación, una yunta, acompañada de diversos aperos para el corte de la hierba, así como un comedero de madera. A continuación, están representados, en una gran vitrina, los oficios del herrero, el carpintero, el alpargatero, el hilandero y el costurero. Se puede ver también el mostrador de una tienda y, en el exterior, diversos aperos de labranza. Esta planta baja cuenta también con una pequeña sección destinada a los monumentos megalíticos del Baztan, en la que se destaca la figura de Barandiarán. En la exposición de la primera planta hay secciones destinadas a la indumentaria local, las danzas y la música locales, la religiosidad popular, los deportes (especialmente a las diferentes modalidades de pelota vasca) y a diversas actividades rurales (elaboración del queso o matanza del cerdo, por ejemplo). Hay también recreados un dormitorio y una cocina con fuego bajo que, según se expresa en el tríptico del museo, se trata de una reconstrucción ideal de comienzos del siglo XX. Por último, hay un espacio dedicado a la singularidad administrativa del Baztan.

Por último, en lo que llevamos de década, el número de creación de museos ha disminuido sustancialmente, siendo la presencia de los de folclore y etnografía muy pequeña. De los 17 nuevos museos que hemos registrado, solamente tres se pueden englobar dentro de esa tipología museística. Sin embargo, para cerrar esta diacronía, no nos detendremos en ninguno de esos últimos, sino que volveremos al primer museo creado en el país: al Museo San Telmo. Transcurrido más de un siglo de su apertura al público, el museo se reinauguró en el 2011. Si bien, más que de una reinauguración, se trata una reinvención como museo de sociedad, en la línea de las renovaciones del Musée des civilisations de l'Europe et de la Méditerranée y del Museum Europäischer Kulturen, mencionadas en el primer apartado.

El objetivo de su exposición permanente es presentar "la evolución del individuo en sociedad y [... ofrecer] una reflexión sobre el pasado cultural e histórico como germen de la sociedad actual. [...] En esta exposición se presentan los hitos, comportamientos y formas de pensar y vivir que a lo largo del tiempo han modelado a la sociedad vasca y se ofrecen claves para su interpretación contemporánea”. La exposición cuenta con cinco grandes espacios. Hay uno destinado a la colección histórica de arte. Otro, denominado "Historia del sitio", en el que se presenta la evolución histórica del edificio. En un tercero, "Los desafíos de nuestra sociedad", se abordan diferentes cuestiones a las que se enfrenta la sociedad actual (paz y derechos humanos, desarrollo sostenible, interculturalidad, igualdad de género o el papel de Europa en el mundo). Y, en las dos restantes, "Huellas

5. http://www.santelmomuseoa.com/index.php?option=com_flexicontent\&view=items\&id=66\&cid=0 \&Itemid=70\&lang=es [Consultado el 3 de marzo de 2015]. 
de la memoria" y "Despertar de la modernidad", se hace un recorrido de la evolución del País Vasco. En el primero, desde la prehistoria hasta el siglo XVIII y en el segundo se abordan los siglos XIX y XX.

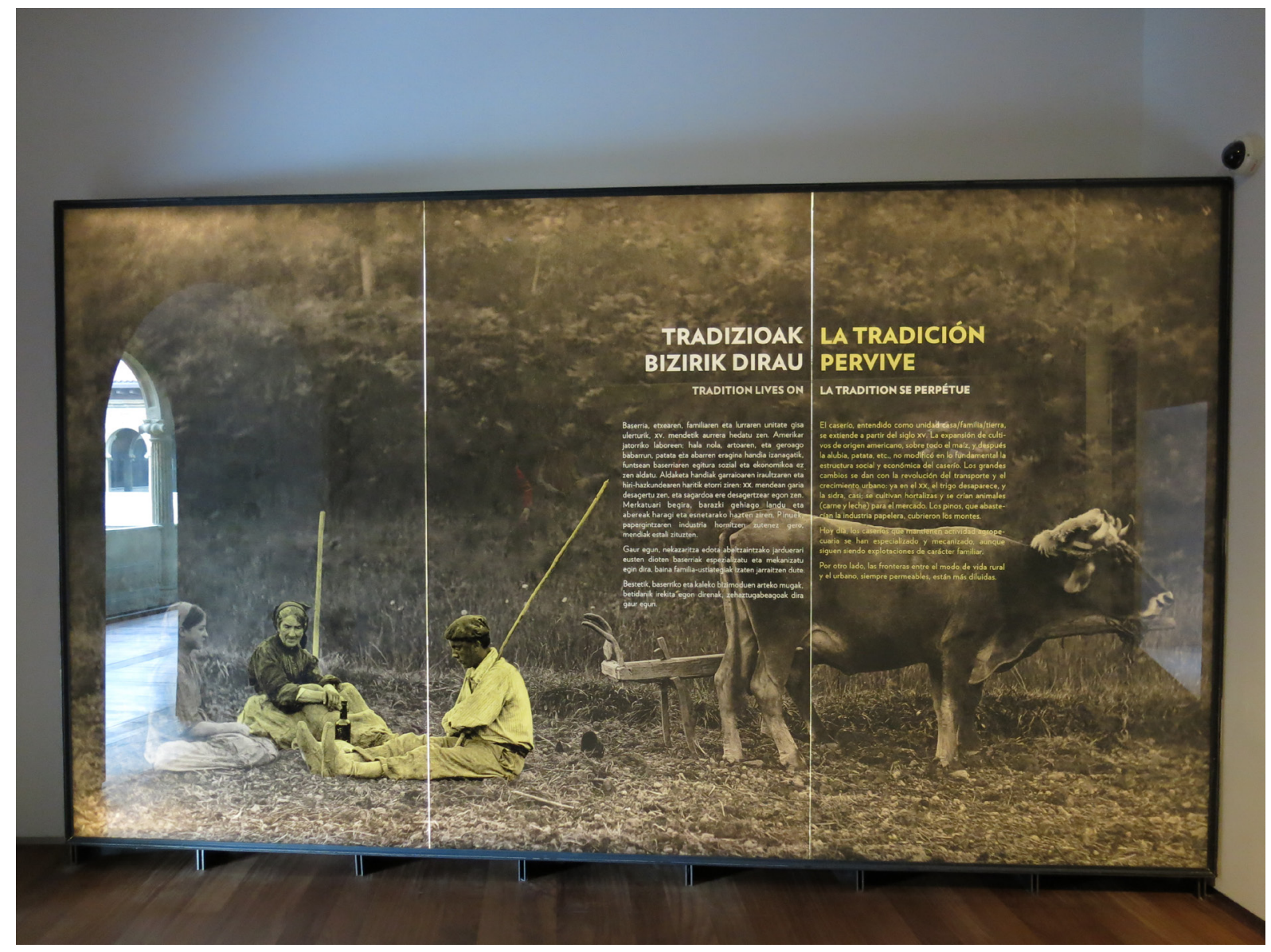

Foto 3: Exposición del Museo San Telmo: "La tradición pervive”. (Foto: Iñaki Arrieta).

En estos dos últimos espacios se han dispuesto el folclore y la etnografía. En "Huellas de la memoria" hay una sección, denominada "Signos de espiritualidad", en la que se presenta un número importante de estelas y argizaiolak o cerilleros de difuntos. Dicha sección arranca con un panel introductorio que recoge la interpretación de Barandiarán acerca de dichos elementos religiosos. Asimismo, en ese mismo espacio expositivo, hay ámbitos museográficos destinados a las ferrerías, la brujería y a la llegada del maíz al País Vasco. Es, no obstante, en el espacio "Despertar de la modernidad", donde se puede advertir mejor el lugar asignado al folclore y al mundo rural en la historia del país. El espacio se denomina "La tradición pervive". La entrada a dicho espacio está presidida por una enorme fotografía en la que se ve una yunta con tres baserritarrak o campesinos descansando. Sobre el cristal que cubre la fotografía hay un panel en el que se informa brevemente de los cambios ocurridos en el caserío a lo largo del siglo XX. El conjunto 
de "La tradición pervive" cuenta con varias salas. La primera está dedicada a la música y la danza tradicionales, tal como se afirma en un panel. A continuación viene la sección dedicada a los deportes vascos como la pelota, el levantamiento y el arrastre de piedra o el remo. En esta sala hay un panel introductorio, titulado "Trabajo y desafío", en el que se define el "deporte rural vasco como 'expresión del trabajo", recogiendo las palabras de Caro Baroja. Aunque en la sala hay algún que otro objeto contemporáneo, el espacio, contextualizado con fotos en blanco y negro, de hace algunas décadas, apunta al carácter tradicional de dichos deportes. A continuación está la sección dedicada a los trabajos del caserío y a los oficios tradicionales de carbonero, pastor y pescador, y hay una pequeña sala donde se recrea una cocina con un fuego bajo de un caserío. Por último, hay una sala con dos secciones. La primera está dedicada a los trabajos del lino. La segunda cuenta con un audiovisual en el que se narra algunos de los cambios acaecidos en el caserío. Esta segunda sección está ataviada con fotos de hace unas décadas, en blanco y negro, mostrando los diferentes contenidos que constituyen todo este espacio dedicado a la tradición. Por último, señalar que, a diferencia de las exposiciones que hemos abordado hasta ahora, los oficios de alpargatero, carpintero o tonelero se encuentran en el espacio dedicado a la industrialización, como precursores de la misma.

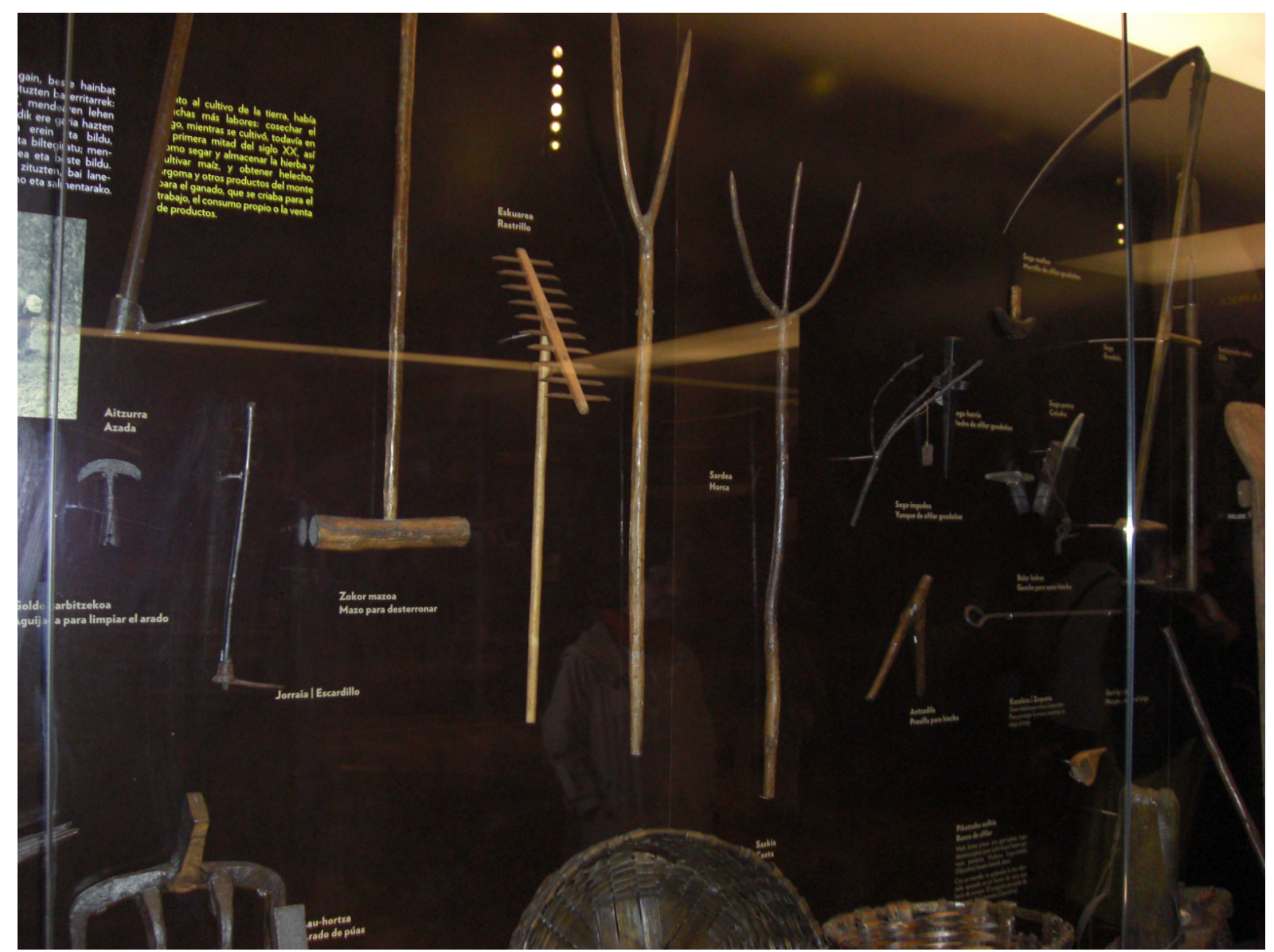

Foto 4: Exposición del Museo San Telmo. 


\section{CONCLUSIONES}

Este breve recorrido a través de la creación de los museos de folclore y etnografía nos muestra qué poco ha cambiado la representación del mundo rural a lo largo de los más de cien años de historia que tienen esos museos. Los contenidos que establecieron los primeros antropólogos vascos, siguiendo la tendencia europea de su tiempo, se han mantenido a pesar de que la sociedad rural haya cambiado drásticamente, y de que el folclore y la etnografía y su objeto de estudio se hayan reformulado considerablemente.

Esta falta de actualización plantea, consideramos, importantes retos para el futuro de esas infraestructuras patrimoniales. Aunque la figura del caserío tradicional siga siendo un referente identitario de primer orden para algunas opciones ideológicas actuales, su representación en los museos no tiene el atractivo que tenía en las primeras décadas o en los años 80 o 90 del pasado siglo.

Por otro lado, el hecho de no abordar cuestiones actuales que afectan al ámbito rural, en particular, y a la sociedad, en general, rechazando la modernidad y la posmodernidad, dificultan que las nuevas generaciones se vinculen a los contenidos expositivos. La falta de puentes entre el presente vivido y el pasado expuesto hace que dicho pasado se considera cada vez más extraño. En cierta medida, toda esta problemática no es nueva. Ya se dio con el Museo de Artes y Tradiciones y Populares en París, cuando abrió sus puertas al público en 1972 y tuvo que cerrarlas en 1985, ante la indiferencia de los franceses y de los turistas.

Además, aunque siempre haya matices en los contenidos expuestos, hay una cierta reiteración en el guión de las exposiciones, dando pie a una cierta saturación en la oferta museística. Lo que nos lleva a preguntarnos si son un recurso eficiente a la hora de atraer al turismo cultural y, por lo tanto, de favorecer el desarrollo local; el leimotiv de la creación de muchos de estos museos, especialmente a partir de comienzos de este siglo. Para concluir, como sostienen Kavanagh (1991:191) y Marshall (1977:395), hay que reconocer todo el trabajo que se ha realizado, y se continúa realizando, en la recogida del patrimonio rural, aunque dicho trabajo presente en no pocos casos lagunas metodológicas importantes. Tampoco podemos olvidar las iniciativas que en museos como en los de Zerain, Igartubeitia, San Telmo o de Euskal Herria se llevan a cabo para abordar temas actuales de la sociedad rural o del folclore. Sin embargo, si los museos de folclore y etnografía continúan sin abordar en sus exposiciones el presente y el futuro, centrándose únicamente en el pasado, si siguen sin establecer puentes entre estos tres tiempos, su destino como instituciones culturales significativas para las sociedades actuales, se presenta, pensamos, bastante complicado. 


\section{REFERENCIAS BIBLIOGRÁFICAS}

Aguirre Sorondo, Antxon (2002) "El museo etnográfico vasco". En San Telmo: crónica de un centenario. Oiartzun: Michelena, pp. 109-137.

Apaolaza, José Miguel (1987) "Zalduondo. Proceso de formación de una identidad". Kobie 2, pp. 151-178.

Aranzadi, Telesforo (1910) "Museos de folk”. En España Moderna, pp. 5-32.

Aranzadi, Telesforo (1911) Antropología y etnología del País Vasco-Navarro. Barcelona: Casa editorial de Alberto Martín.

Asociación Etnográfica Atea (2011) Museo etnográfico de Artziniega. Memoria: 19842009. Artziniega: Asociación Etnográfica Artea.

Arregi, Gurutz (1999) "El patrimonio cultural en la obra de don José Miguel de Barandiarán”. Cuadernos de etnología y etnografía de Navarra 73, pp. 343-353.

Arrieta Urtizberea, Iñaki (2006) "Elites, instituciones públicas, identidad cultural y turismo en los orígenes del Museo Municipal de Donostia-San Sebastián”. En I. Arrieta (ed.) Museos, memoria y turismo, Bilbao: Universidad del País Vasco, pp. 45-76.

Azcona, Jesús (1984) Etnia y nacionalismo vasco: una aproximación desde la antropología. Barcelona: Anthropos.

Barandiarán Irízar, Felipe (1984) José de Miguel de Barandiarán: patriarca de la cultura vasca. Donostia-San Sebastián: Sociedad Guipuzcoana de Ediciones y Publicaciones.

Caro Baroja, Julio (1944) Proyecto para una instalación al aire libre del Museo del Pueblo Español. Madrid: Museo del Pueblo Español.

Caro Baroja, Julio (1958) "Plan de instalación del museo etnográfico y arqueológico de Bilbao”. Munibe X (3), pp. 15-131.

Caro Baroja, Julio (1971) Los Vascos. Madrid: Istmo.

Castilla Urbano, Francisco (2002) El análisis social de Julio Caro Baroja: empirismo y subjetividad. Madrid: CSIC.

Chaumier, Serge (2005) "L'identité, un concept embarrassant, constitutif de l'idée de musée”. Culture et musées 6, pp. 21-42.

Chevallier, Denis; Chiva, Isac y Dubost, Françoise (2000) "Linvention du patrimoine rural", Autrement. Série mutations 194, pp. 11-55.

Grande, Mario (1978) El museo histórico de Vizcaya. Bilbao: Caja de Ahorros Vizcaína. Crooke, Elizabeth (2007) Museums and Community: ideas, issues and challenges. Londres y Nueva York: Routledge. 
Davis, Peter (2011) Ecomuseums: a Sense of Place. Londres y Nueva York: Continuum. Desvallees, André (2000) “Introduction”. Publics et Musées 17-18, pp. 11-31.

Díaz Balerdi, Iñaki (2008) "Museos en la encrucijada: estructuras, redes y retos en el país vasco”. En X. Roigé, E. Fernández de Paz e I. Arrieta (coords.) El futuro de los museos etnológicos: consideraciones introductorias para un debate. Donostia-San Sebastián: Ankulegi Antropologia Elkartea, pp. 69-86.

Díaz Balerdi, Iñaki (2010) Archipiélagos imaginarios: museos de la Comunidad Autónoma del País Vasco. Vitoria-Gasteiz: Nerea y Servicio Central de Publicaciones del Gobierno Vasco.

Duclos, Jean-Claude y Veillard, Jean-Yves (1992) "Museos de etnografía y política". Museum 175, pp. 129-132.

DUNCAN, Carol (2007) Rituales de civilización. Murcia: Nausícaä.

Errekondo, Jakoba (2001) “Zerain, paisaje cultural”. Revista Ambienta 97 http://www. revistaambienta.es/WebAmbienta/marm/Dinamicas/secciones/articulos/Zerain.htm [Consultado el 9 de marzo de 2015].

García García, José Luis (1998) "De la cultura como patrimonio al patrimonio cultural". Política y Sociedad 27, pp. 9-20.

Gaya Nuño, Juan Antonio (1955) Historia y guía de los museos de España. Madrid: Espasa-Calpe.

Goenaga Maiza, N.; Vives Almandoz, G.; Ugarteburu Plazaola, K. y Azpiazu Aizpeola, L. (2007) "El Caserio Museo Igartubeiti". ICOM Digital 7, pp. 46-73. http://www.icom-ce. org/recursos/ICOM CE Digital/07/ICOM\%20CE\%20Digital\%2007.pdf [Consultado el 12 de marzo de 2015].

Goicoechea Marcaida, Ángel (1984) "La antropología cultural en Aranzadi". Cuadernos de sección: Antropología-Etnografía 5, pp. 192-213.

Goicoechea Marcaida, Ángel (1985) Telesforo de Aranzadi: vida y obra. Donostia-San Sebastián: Sociedad de Ciencias Aranzadi.

Gorgus, Nina y Chabaud, Véronique (200) "L'Heimatmuseum, lécomusée et G. H. Rivière". Publics et Musées 17-18, pp. 57-69.

Izaguirre, Manu (2003) "La intervención en el caserío Igartubeiti". En Un caserío guipuzcoano: investigación, restauración, difusión. Donostia-San Sebastián: Gipuzkoako Foru Aldundia, pp. 107-134

Jong, Adriaan de y Skogaard, Mette (1992) "Los primeros museos al aire libre. La tradición de los museos de tradiciones”. Museum 175, pp. 151-157. 
Kavangh, Gaynor (1991) "Mangles, Muck and Myths: Rural History Museums in Britain". Rural History 2 (2), pp. 187-203.

Leizaola, Fermín (1997) "El proyecto de exposiciones Zaharkiñak". En Vers un réseau des musées pyrénées? Toulouse: Addoc Midi-Pyrénées, pp. 397-404

Lorenzo, Felicitas (2007) "Nuestra prioridad es buscar la rentabilidad social del museo". Euskonews 418, http://www.euskonews.com/0418zbk/menu.html [Consultado el 3 de marzo de 2015].

Lowenthal, David (1998) El pasado es un país extraño. Madrid: Akal.

Mairesse, François (2011) "Musée”. Dictionnaire encyclopédique de muséologie. París: Armand Colin, pp. 271-320

Marshall, Howard Wight (1977) "Folklife and the Rise of American Folk Museums". Journal of American Folklore 90 (358), pp. 391-493.

Maze, C., Poulard, F. y Ventura, C. (2013) "Démantèlements, reconversions, créations. Contribution à l'analyse du changement institutionnel”. En Les Musées d'ethnologie. Culture, politique et changement institutionnel. París: CTHS, pp. 9-33.

Mujika Goñi, Amaia (1995) “Los museos etnográficos en el País Vasco: Una visión general y un proyecto particular. El Museo Arqueológico, Etnográfico e Histórico Vasco”. Anales del Museo Nacional de Antropología 2, pp. 283-299.

Museo Arqueológico, Etnográfico e Histórico Vasco (1996) Museo Arqueológico, Etnográfico e Histórico Vasco 1921-1996: breve sintesis histórica. Bilbao: Museo Arqueológico, Etnográfico e Histórico Vasco.

Noyes, Dorothy (2012) “The Social Base of Folklore”. En Regina F. Bendix y Galit HasanRokem (eds.) A Companion to Folklore. Nueva York: Wiley-Blackwell, pp. 13-39.

Ortiz, Carmen y Prats, Llorenç (2000) "La question du patrimoine". Ethnologie française XXX, pp. 241-249.

Poulot, Dominique (2005) Musée et muséologie. París: La Découverte.

Prat, Joan (1991) “Introducción”. En J. Prat, U. Martínez, J. Contreras e I. Moreno (eds.) Antropología de los pueblos de España. Madrid: Taurus, pp. 13-32.

Prat, Joan (1994) “Folklore”. En C. Ortiz y L.A. Sánchez (eds.) Diccionario histórico de la antropología española. Madrid: CSIC, pp. 310-313.

Rautenberg, M., Micoud, A., Berard, 1. y Marchenay, P. (2000) "Introduction". En Campagnes de tous nos désirs: patrimoines et nouveaux usages sociaux. París: Maison des sciences de l'Homme, pp. 1-10. 
Riviere, Georges-Henri (1936) "Les musées de folklore à létranger et le futur musée des arts et traditions populaires". Revue de folklore français et de folklore colonial 7, pp. 58-71. Riviere, Georges-Henri (1985) “Definición evolutiva del ecomuseo”. Museum 148 (4), pp. 58-71.

Rogan, Bjarne (2003) “The Emerging Museums of Europe”. Ethnologia Europaea 33 (1), pp. 51-59.

Roigé, Xavier (2007) “La reinvención del museo etnológico". En I. Arrieta (ed.) Patrimonios culturales y museos: más allá de la Historia y del Arte. Bilbao: Universidad del País Vasco, pp. 18-42.

Rougé, X., Boya, J. y Alacalde, G. (2010) "Els nous museus de societat: redefinint models, redefinint identitats". En Museus d'avui: els nous museus de societat. Girona: Institut Català de Recerca en Patrimoni Cultural, pp. 155-195.

Santana, Alberto (2003) "Historia del caserío Igartubeiti". En Un caserío guipuzcoano: investigación, restauración, difusión. Donostia-San Sebastián: Gipuzkoako Foru Aldundia, pp. 25-106

Smith, Anthony D. (2000) Nacionalismo y modernidad: un estudio crítico de las teorías recientes sobre naciones y nacionalismo. Madrid: Istmo.

Urla, Jacqueline y Errekondo, Jakoba (2010) "Zerain.com: Cultural landscape as a framework for integrating sustainable economic futures, heritage and language preservation" http://scholarworks.umass.edu/efsp_pub_articles/12/ [Consultado el 9 de marzo de 2015].

Velasco, Honorio (1990) “El folklore y sus paradojas”. REIS 49, pp. 123-144.

Williams, Raymond (2003) Palabras clave: un vocabulario de la cultura y la sociedad. Buenos Aires: Nueva Visión.

Zulaika, Joseba (2000) Del Cromañón al Carnaval: Los vascos como museo antropológico. Donostia-San Sebastián: Erein. 